\title{
The antecedents of response strategies in strategic alliances
}

\author{
Brian Tjemkes \\ Vrije Universiteit Amsterdam, Amsterdam, The Netherlands, and \\ Olivier Furrer \\ Radboud University Nijmegen, Nijmegen, The Netherlands
}

\begin{abstract}
Purpose - Strategic alliances involve uncertainty, interdependence, and vulnerability, which often create adverse situations. This paper seeks to understand how alliance managers respond to these adverse situations by examining the influence of four exchange variables on response strategies.

Design/methodology/approach - A scenario-based experiment provides empirical support for a typology consisting of seven conceptually and empirically distinct response strategies: exit, opportunism, aggressive voice, creative voice, considerate voice, patience, and neglect.

Findings - The results indicate that economic satisfaction, social satisfaction, alliance-specific investments, and the availability of attractive alternatives differentially and interactively affect response strategies.

Research limitations/implications - The study offers two main contributions to alliance literature. First, the seven response strategies accurately represent reactions that alliance managers use to deal with adverse situations. Second, the study findings validate and extend previous alliance research by highlighting that a comprehensive response strategy typology is necessary to disentangle the effects of the four exchange conditions on response strategy use, which fosters theory development and managers' ability to manage their alliances effectively.

Originality/value - The study contributes to the process perspective on strategic alliances by highlighting the various response strategies that alliance managers use to deal with adverse situations and their antecedents.
\end{abstract}

Keywords Strategic alliances, Managers

Paper type Research paper

\section{Introduction}

The past several decades have witnessed enormous growth in alliance activity (Das and Kumar, 2010), and strategic alliances apparently have established themselves as cornerstones for the competitive strategy of many firms, enabling those firms to achieve objectives that otherwise would be difficult to realize (Das and Teng, 2000). However, alliances still tend to exhibit a mix of promise and peril. Whereas alliances enable firms to capitalize on opportunities, managers must remain responsive to the threat of adverse situations. For example, alliance managers may need to resolve dissatisfying alliance performance issues, improve poor working relationships, and deal with the negative consequences of exit barriers, such as alliance-specific investments and a lack of attractive external alternatives. Alliance managers also must respond to avoid the premature termination of the alliance, which may hamper the realization of their firms' strategic objectives (Das and Kumar, 2007; Makino et al., 2007). The high failure rate of alliances (e.g. Hoang and Rothaermel, 2005) demands a better understanding of responses to adverse situations and their determinants. To make this contribution to alliance literature, we formulate two research questions: 
(1) What is the range of response strategies from which alliance managers can choose?

(2) When do they use these different response strategies?

Consistent with previous alliance studies (Buckley, 1999; Geyskens and Steenkamp, 2000; Griffith, 2006), we define a response strategy as a reaction to an adverse situation. Although extant empirical research demonstrates that managers use various response strategies to overcome adverse situations (e.g. Ariño and De la Torre, 1998; Brouthers and Bamossy, 2006), a comprehensive typology of response strategies in the alliance context remains lacking. Most alliance studies focus a single type of responses, such as alliance termination (Park and Ungson, 1997), opportunistic behavior (Deeds and Hill, 1998), or voice (Ping, 1997). Such focused approaches undermine the development of an integrative vision that might clarify alliance managers' alternative use of response strategies. To overcome this shortcoming, several studies adopt response strategy typologies from other fields (e.g. Geyskens and Steenkamp, 2000; Ping, 1993, 1999), yet those typologies include a limited number of generic responses (e.g. exit, voice, loyalty, neglect) and cannot cover the full range of alternative responses used by alliance managers. Anecdotal evidence suggests that managers respond to adverse situations in ways that existing typologies describe only poorly, hampering further theory development. To overcome this limitation, we extend the exit-voice-loyalty-neglect (EVLN) typology (Farrell, 1983; Rusbult and Zembrodt, 1983) with three additional responses: creative voice, aggressive voice, and opportunism.

To recognize when alliance managers are more likely to use particular response strategies, we also extend prior alliance research by investigating the effect of adverse situations according to the impact of four exchange variables: economic satisfaction, social satisfaction, alternative attractiveness, and alliance-specific investments. The simultaneous examination of these four exchange conditions enables us to disentangle confounding effects; to the best of our knowledge, no previous alliance study examines these variables in a single study. For example, Ping (1993) considers the effect of overall satisfaction, alternative attractiveness, and investments, and Geyskens and Steenkamp (2000) distinguish between economic and social satisfaction, but neither examines other exchange variables. Whereas Ping's (1997) results indicate that overall satisfaction positively influences the use of voice, Geyskens and Steenkamp (2000) report that social satisfaction, not economic satisfaction, relates to voice. Moreover, their findings suggest that economic and social satisfaction directly and interactively influence response strategies. Thus, research needs to consider the interaction between economic and social satisfaction. Regarding the effect of exit barriers, Ping $(1993,2003)$ reveals that investments and alternative attractiveness differentially affect the use of response strategies, such that alternative attractiveness significantly influences exit, opportunism, and neglect, whereas investments significantly influence voice and neglect. Therefore, it is important to distinguish the effects of the two different types of exit barriers, as well as their interaction. By proposing and assessing an extended typology of response strategies to adverse situations in strategic alliances and then examining the conditions in which particular responses are more likely, we contribute to alliance process literature (e.g. Gulati et al., 1994) and provide a finer-grained understanding of the postformation responses used by managers who face adverse situations. 
The remainder of this article is organized as follows: First, we identify the need for an extended typology of seven response strategies. Second, on the basis of a review of alliance research on response strategies, we develop a set of hypotheses that relate the four exchange variables to each response strategy. Third, we explicate the experimental design we use to test the hypotheses. Fourth, we present the results and conclude with a discussion of the academic and managerial implications of the results, as well as directions for further research.

\section{Responses to adverse situations in strategic alliances}

A recurring theme in alliance literature pertaining to post-formation processes relates to how managers respond to adverse situations as a means to achieve alliance goals and improve performance (Ariño and De la Torre, 1998; Doz, 1996). For example, Doz (1996) indicates that to succeed over time, alliances must adapt their tasks, routines, performance expectations, and objectives. Ariño and De la Torre (1998) also identify different adjustment or response strategies that managers use to adapt an alliance, improve performance, and avoid premature termination. If alliance partners cannot reach an agreement, the aggrieved partner must take unilateral corrective action, which likely deteriorates the relationship. Other studies show that alliance managers overcome adverse situations by implementing constructive adaptations (Brouthers and Bamossy, 2006; Reuer and Ariño, 2002). However, these studies consistently focus on explaining alliance performance rather than understanding managers' reactions. To explicate alliance managers' reactions, a particular stream of alliance research (e.g. Geyskens and Steenkamp, 2000; Hibbard et al., 2001; Ping, 1993) borrows a typology of response strategies originally developed by Hirschman (1970) to explain the responses of organizations to declining performance and furthered in various other management fields.

Response strategies: the ELVN typology

Hirschman's (1970) exit, voice, and loyalty framework provides the foundation for an important stream of research regarding response strategies. Hirschman initially represented exit, voice, and loyalty as three alternative strategies along a constructive-destructive spectrum (Leck and Saunders, 1992). Extending Hirschman's framework with a fourth strategy, namely neglect, Farrell (1983) and Rusbult and Zembrodt (1983) propose the ELVN (exit-voice-loyalty-neglect) typology, which represents a parsimonious conceptualization of response strategies and derives its strength from the underlying two-dimensional structure into which the four response strategies are organized: an active-passive dimension and a constructive-destructive dimension. The alliance context defines the four EVLN response strategies as follows.

Exit, an active-destructive response, indicates a disinclination to continue the current relationship (Ping, 1999). Alliance literature thus refers to exit as an alliance termination (e.g. Makino et al., 2007; Park and Ungson, 1997) that represents the ultimate and most destructive response to an adverse situation; once the alliance is dissolved, partner firms must find alternative ways to achieve their objectives. Voice is an attempt to overcome the adverse situation by considering own concerns, as well of those of the other party (Ping, 1997, 2003), such that alliance managers actively and constructively discuss the situation with the intent to develop mutually satisfactory solutions (Geyskens and Steenkamp, 2000; Hibbard et al., 2001). Therefore, voice 
represents an active attempt to change, rather than escape from, the situation by contacting the partner in a relationship-preserving manner and cooperatively discussing the problem (Ping, 1999). However, in silently abiding issues, with the confidence that things will improve in the future (Geyskens and Steenkamp, 2000; Hibbard et al., 2001; Ping, 1993), loyalty (also called patience[1]) provides a constructive-passive response. Managers voluntarily ignore the issue and hope that the adverse situation resolves by itself, so they consider undesirable circumstances transitory phenomena that will dissipate over time (Ping, 1993). Finally, neglect, a passive-destructive response, involves allowing the relationship to deteriorate (Ping, 1993, 1999). A neglectful manager expends little effort to maintain the alliance (Pressey and $\mathrm{Qu}, 2007$ ), and possible ways to solve the situation get ignored, such that the relationship eventually dies (Ping, 1993).

Because they developed in contexts other than strategic alliances, the four EVLN strategies do not address the entire range of alternatives actually used by alliance managers. For the typology to correspond to the alliance context, we need to add the strategies that alliance managers use, as identified in alliance literature. As Rusbult et al. (1988) suggest, the ELVN typology may serve as a common framework into which research should incorporate additional responses adapted to specific contexts.

\section{Additional response strategies}

Extending previous alliance research based on the EVLN typology (Geyskens and Steenkamp, 2000; Ping, 1993), we propose the addition of three supplementary response strategies: aggressive voice, creative voice, and opportunism. Hirschman (1970, p. 39) initially conceptualized voice in a relatively neutral manner as "any attempt at all to change, rather than to escape an objectionable state of affairs". In the EVLN typology, voice mostly suggests a positive approach, involving the constructive discussion of issues with the intent to find mutually satisfactory solutions (e.g. Ping, 1993). However, empirical studies (e.g. Rusbult et al., 1988; Withey and Cooper, 1989) report low internal consistency for voice, suggesting that it might be a more complex construct with several subcomponents (Kay, 1989; Withey and Cooper, 1989). In addition to its positive dimension, voice may have a negative connotation, such as direct aggressive criticism or coercion (Hagedoorn et al., 1999; Hibbard et al., 2001). Moreover, expressions of voice might be aimed at developing creative and innovative solutions (e.g. Kay, 1989; Zhou and George, 2001). Following Hagedoorn et al. (1999), we call the EVLN type of voice "considerate" and define it as a manager's active efforts to seek to resolve an adverse situation by contacting a counterpart in a relationship-preserving manner and cooperatively discussing the problem to improve the situation (Ping, 1999). Das and Kumar (2010) refer to this type of voice as inter-partner sensemaking. We therefore distinguish this type of voice from two other forms: aggressive and creative.

Aggressive voice refers to an active-destructive response strategy that consists of persistent efforts by one partner to solve undesirable situations, regardless of the ideas and preferences of the counterpart (Hagedoorn et al., 1999). In an alliance context, aggressive voice suggests managers forcefully impose their solutions, without trying to avoid conflicts (Hibbard et al., 2001). Anecdotal evidence indicates that alliance managers may coerce partners into one-sided solutions (Ariño and De la Torre, 1998; De Rond and Bouchikhi, 2004; Doz, 1996). For example, De Rond and Bouchikhi (2004), 
p. 62) analyze the formation and development of a strategic alliance between two pharmaceutical firms (Plethora and Rummidgen, not real names) and describe several examples of the use of aggressive voice: "Rummidgen persisted, and [...] persuaded Plethora to abandon mixtures in favor of a single-compounds approach" or "Rummidgen now demanded a 20 per cent increase in funding above and beyond the sum agreed with Plethora two years earlier". These illustrations highlight not only that aggressive voice is one of multiple possible responses in strategic alliances but also that it is conceptually different from considerate voice (Hibbard et al., 2001).

Creative voice, the third type, refers to the generation of novel and potentially useful solutions to an adverse situation (Zhou and George, 2001). In a qualitative study, Kay (1989) finds that prototypical voice behaviors include "propose new ways of doing things" and "make suggestions on how to improve things", both of which are consistent with definitions of creativity. In an alliance context, creativity or creative voice consists of a partner trying to overcome the adverse situation through innovative solutions (Brouthers and Bamossy, 2006; Doz, 1996). Ariño and De la Torre (1998) indicate that during the start-up phase of a joint venture, partners exhibit willingness to find innovative solutions, beyond the scope of their contractual agreement, to align their interests and preserve the relationship. Doz (1996) also demonstrates that partners proceed through learning cycles that enable them to develop creative solutions to deal with adverse situations. Creative voice therefore differs from aggressive voice with respect to purpose: Whereas creative voice is constructive and takes into account the counterpart's interests, aggressive voice is more destructive and focuses on the interests of the manager's own firm. Creative and considerate voices also are conceptually distinct, in that creative voice pertains to the intention to seek out-of-the-box solutions rather than cooperatively discuss the problem to improve the situation.

Opportunism as a response strategy also represents an active-destructive response (Wathne and Heide, 2000). Ping (1993) defines opportunism as the intention to increase a partner's benefits from the relationship in ways that are explicitly or implicitly prohibited within the relationship. This type of response includes shirking, the use of the circumstances to extract concessions from the other party, the evasion of obligations, and the withholding of critical information (Das, 2005; Wathne and Heide, 2000). Several studies examine opportunism within the context of strategic alliances and argue that it constitutes a distinct response (Deeds and Hill, 1998; Doz, 1996; Johnson et al., 1996; Judge and Dooley, 2006; Luo, 2007). For example, in an examination of pharmaceutical alliances, Doz (1996, p. 72) reports comments such as, "we knew they were doing some work on TTS that they would not share with us ..., we always felt that CG had information they should have fed back to us, but did not" and "CG lacked confidence that we could turn ourselves around. They started making openings to our people". Opportunism occurs when a partner seeks to maximize its individual returns at the expense of its partners (Deeds and Hill, 1998), which makes it conceptually different from aggressive voice. Although both responses imply that a partner has the intention to pursue its individual interests, aggressive voice directly targets the firm's counterpart and attempts to coerce it to complying with its demands, whereas opportunism is covert behavior aimed at deceiving the counterpart (John, 1984; Joshi and Arnold, 1997). 


\section{Hypothesis development}

Prior research on the EVLN typology in an alliance context identifies not only different types of responses but also their antecedents. In previous studies, social exchange theory (Blau, 1964; Cropanzano and Mitchell, 2005) and interdependence theory (Thibaut and Kelley, 1959) provide the dominant theoretical perspectives used to examine the effects of such antecedents. Drawing on these theories, Rusbult et al. (1982) develop and find empirical support for an investment model in which three exchange variables influence the conditions most likely to initiate a response: the degree of satisfaction with the relationship, the magnitude of investment of resources in the relationship, and the quality of the best available alternative to the relationship. We distinguish among four similar exchange variables: economic satisfaction, social satisfaction, alliance specific investments, and availability of alternatives.

Each exchange variable represents a manifestation of the adverse situations alliance managers likely confront. Poor economic satisfaction demands a response, because it endangers firms' long-term performance; poor social satisfaction prompts managers to respond because it increases the costs of managing the alliance. In terms of exit barriers, both alliance-specific investments and the lack of attractive alternatives outside the alliance increase the costs of terminating the alliance by creating potential hold-up situations. Alliance-specific investments constitute a source of dependence, opening the door to exploitation (Klein et al., 1978), which pushes managers to respond and restore a balance of power to protect their investments. The lack of alternatives also creates a potential hold-up situation, but managers likely respond to it differently, because such dependence increases the relative value of the relationship and should stimulate managers to act in the interest of the alliance. Thus, managers are likely to respond, though differently, to all four-exchange conditions.

We base our hypotheses on the assumption of an ongoing strategic alliance between two partner firms engaged in a long-term relationship. The level of analysis therefore considers a manager responding to an adverse situation related to the alliance (Chatman, 1989). In this context, managers assess the exchange context and respond to adverse situations to achieve their firms' strategic objectives.

\section{Economic satisfaction}

Economic satisfaction represents a partner's evaluation of the financial outcomes of the relationship (Cropanzano and Mitchell, 2005; Geyskens and Steenkamp, 2000). According to Geyskens et al. (1999), an economically satisfied manager considers the alliance a success with respect to goal attainment, effectiveness, productivity, and the resulting financial outcomes. Low economic satisfaction implies that partners perceive a discrepancy between prior expectations and desired financial results (Geyskens et al., 1999), which requires managers to respond to the situation to achieve their firm's alliance objectives.

As Geyskens and Steenkamp (2000) argue, when economic satisfaction is low, managers tend to perceive the alliance as less valuable and may not respond constructively. Furthermore, because poor financial performance endangers shareholder value, managers likely respond actively rather than passively; this poor financial performance creates a sense of urgency that forces managers to adopt responses aimed at improving the situation rapidly (Das, 2005, 2006). Neglecting the situation or waiting patiently for an improvement is less likely, because these response 
strategies may lead to further financial distress. Managers are also less likely to use considerate voice, which may be too slow to turn around the situation. In contrast, creativity often results from the pressure of an immediate need to find a solution (Amabile, 1988), and poor economic satisfaction may prompt alliance managers to "rock the boat" by using aggressive voice and opportunism to restore performance or extract additional benefits from the alliance quickly (Dwyer et al., 1987; Ping, 1993). If they perceive that it is too costly or time-consuming to improve the situation, managers may give up and exit the alliance (Lewis and Lambert, 1991).

Some of these relationships receive support in empirical studies. For example, Geyskens and Steenkamp (2000) find that in marketing channel relationships, economic satisfaction positively influences loyalty (i.e. patience) and negatively affects exit. However, the relationship between economic satisfaction and voice is not significant, probably because they operationalize voice as a mixture of considerate and creative factors. Both these authors and Ping (1993) find a slight negative relationship between economic satisfaction and neglect and argue that the value of the alliance increases with its financial performance, which should reduce negligence. However, we posit that when alliance performance is poor, negligence may not be an option for improving the situation and therefore expect a positive relationship between economic satisfaction and neglect. Furthermore, in a study of retailers' response intentions, Ping (1993) reveals that overall satisfaction, which includes an economic component, is significantly and negatively associated with exit but positively associated with a considerate form of voice (see also Ping, 1997, 1999). No significant relationship emerges with opportunism or patience, probably due to Ping's use of a broad measure of overall satisfaction instead of economic satisfaction, as suggested by Geyskens and Steenkamp (2000). The relationship between economic satisfaction and exit also receives support from Delios et al. (2004), who indicate that poor long-term economic performance eases the trajectory toward alliance termination, and by Olk and Young (1997), who find that satisfaction with the alliance performance positively influences continuity. In addition, Lee et al. (2007) confirm the relationship between economic satisfaction and considerate voice; in the importer-exporter relationships in their study, an importer's economic satisfaction positively influences benevolence, which they define as showing consideration and sensitivity to the needs of the partner.

Finally, several studies find anecdotal support for the effect of economic satisfaction on other response strategies. For example, Brouthers and Bamossy (2006), studying post-formation processes in international joint ventures, indicate that alliance managers who report poor performance compared with those who claim strong performance exhibit fewer efforts to develop innovative processes, build trust, or optimize management control (i.e. creative voice) but more use of aggressive voice, such as threats of legal action. In a marketing channel, John (1984) also describes a positive relationship between retail dealers' economic satisfaction and opportunism. Therefore, we hypothesize:

H1 Compared with alliance managers who perceive low economic satisfaction, alliance managers who perceive high economic satisfaction are less likely to exit, behave opportunistically, and use aggressive and creative voices but are more likely to use considerate voice, be patient, and be neglectful. 
Social satisfaction

Social satisfaction pertains to managers' evaluation of the psychosocial aspects of the relationship; it implies that interactions with partners are fulfilling, gratifying, and facile (Geyskens et al., 1999; Geyskens and Steenkamp, 2000). An important aspect of social satisfaction thus involves managers' perception of the relational quality of their alliances. Partners satisfied with the relationship appreciate contacts with their counterparts, and the relationship likely is characterized by trust, respect, and commitment (Ariño et al., 2001). Alliances characterized by poor relational quality suffer dysfunctional conflicts, distrust, and low commitment, which is, low social satisfaction (Anderson and Narus, 1990). To achieve their firms' strategic objectives, alliance managers likely respond to situations of low relational quality, which increase the costs of managing and monitoring partners (Lui and Ngo, 2004).

Social satisfaction builds over the long run when partners work together (Ariño et al., 2001). Because rebuilding damaged relational quality may be too time consuming, managers dissatisfied with the relationship quality of an alliance may disengage or terminate the relationship rather than try to save it through constructive responses. Furthermore, low social satisfaction creates greater suspicion about the intentions of the partner and results in reduced expectations about the future benefits of the relationship. Without trust, respect, and commitment, managers become less worried about endangering the relationship and may act opportunistically to extract additional benefits (Deeds and Hill, 1998). They also tend to see little hope for a quick recovery and reduce their level of commitment and cooperation, which eventually results in neglectful behaviors (Geyskens and Steenkamp, 2000). Alliance managers may believe that aggressive voice, though unlikely to result in a substantial improvement, still provides some psychic benefits (Hibbard et al., 2001), because it enables them to communicate their dissatisfaction. Therefore, low relationship quality should result in less constructive responses (Anderson and Narus, 1990; Brouthers and Bamossy, 2006) and lesser usage of creative or considerate voice (Geyskens and Steenkamp, 2000). The relationship between social satisfaction and patience may be more complex though. Hibbard et al. (2001) argue that managers with positive views of the relationship place less importance on the adverse situation and remain patient, believing that the transient negative situation will improve. Yet, Geyskens and Steenkamp (2000), contrary to their expectations, find that loyalty (i.e. patience) declines, as-a-result of social satisfaction. They therefore argue that passivity may be acceptable when economic satisfaction is high but not when the relationship is socially satisfying, which instead calls for more active and constructive responses. We follow their argument.

In a marketing channel context, Geyskens and Steenkamp (2000) show that social satisfaction relates negatively to exit, patience, and neglect and positively to voice, which they operationalize as considerate (e.g. try to discuss the problem, talk constructively about how we feel about the situation) and creative (e.g. try to solve the problem by suggesting changes) terms. Their results receive support from Hibbard et al. (2001), who also find a positive association between social satisfaction and considerate voice but a negative relation to exit and neglect. However, they find a positive relationship between social satisfaction and patience. In addition, the negative relationship that Hibbard et al. (2001) hypothesize between social satisfaction and aggressive voice is not significant. Furthermore, several studies provide indirect 
support for a negative relationship between social satisfaction and opportunism: Dwyer et al. (1987) indicate that a high-quality relationship involves minimal opportunism, Judge and Dooley (2006) report a negative association between trust and opportunism, and Deeds and Hill (1998) find that relational quality serves as an effective deterrent to opportunistic behavior. Therefore, we hypothesize:

H2 Compared with alliance managers who perceive low social satisfaction, alliance managers who perceive high social satisfaction are less likely to be patient or neglectful, exit, behave opportunistically, and use aggressive voice but are more likely to use creative and considerate voices.

\section{Interaction between economic and social satisfaction}

Geyskens and Steenkamp (2000) argue that economic and social satisfaction represent two different routes for alliance partners to achieve alliance objectives. When economic satisfaction is low, the effect of social satisfaction becomes more important, and vice versa. According to their results, the likelihood of destructive response strategies declines with economic satisfaction and social satisfaction, and social satisfaction is more effective in discouraging destructive responses in the face of low economic satisfaction, though when economic satisfaction is high, social satisfaction has only a weak effect. In addition, when economic satisfaction is low, social satisfaction becomes more important as a positive influence on constructive responses and reducing the likelihood of destructive strategies.

Several studies report interaction effects between economic and social satisfaction. Morgan and Hunt (1994) indicate that when social satisfaction improves, so does the relationship's efficiency, because relational quality enhances the alliance function by positively influencing trust and commitment building. Ariño and De la Torre (1998) also show that a firm can also accomplish its alliance objectives indirectly by creating higher levels of social satisfaction. The insignificant effect Ping (1993) notes between overall satisfaction and loyalty (i.e. patience) may result from a negative interaction effect between the two types of satisfaction, which could have cancelled each other out (Geyskens and Steenkamp, 2000). Therefore, we hypothesize:

H3 A negative interaction effect exists between economic and social satisfaction on an alliance manager's likelihood of using the seven response strategies. When an alliance manager perceives high (low) economic satisfaction, the effect of perceived social satisfaction is weaker (stronger).

\section{Alliance-specific investments}

Alliance-specific investments are sunk costs that cannot be redeployed easily to another relationship without some sacrifice in the productivity of the assets or cost in adapting them to the new context (Klein et al., 1978). When such investments are unilateral and would be lost if the alliance were dissolved, they act as exit barriers (Porter, 1980). Therefore, their presence constitutes a source of dependence (Emerson, 1962; Klein et al., 1978), which Williamson (1993) considers poor managerial practice that reflects myopic decision-making. Such investments create an adverse situation that causes managers to try to preserve the relationship and reduce the negative consequences of their firms' vulnerable position (Emerson, 1962). 
The presence of alliance-specific investments should trigger constructive response strategies and inhibit destructive ones (Hirschman, 1970; Ping, 1993, 2003), because constructive responses, such as patience and constructive and creative voice, enable managers to preserve the benefits from their investments while reducing the risk of losing them were the relationship to terminate prematurely (Ariño and De la Torre, 1998). When alliance-specific investments are high, managers likely contact their partners and work cooperatively to resolve problems and maintain the relationship (Gulati et al., 1994; Ping, 2003). Conversely, by increasing the costs of terminating the alliance, alliance-specific investments reduce the likelihood of exit and any response that could prompt the partner to exit, such as opportunism, aggressive voice, and neglect (Deeds and Hill, 1998; Delios et al., 2004; Wathne and Heide, 2000).

Several empirical studies provide support for the relationships between alliance-specific investments and response strategies. In the context of supply chain management, Ping (1993) reveals that investments positively influence a considerate form of voice and negatively influence neglect. However, he finds no significant relationships with exit, opportunism, or patience, whereas Anderson (1988) cites a relationship with opportunism. Anderson and Weitz (1992) report that alliance-specific investments associate negatively with exit, and Ping (2003) offers support for a positive relationship between investments and a considerate form of voice. Finally, in an organizational context, Farrell and Rusbult (1992) suggest that investments positively influence loyalty (i.e. patience).

Other alliance studies provide additional support: Reuer and Ariño (2002) highlight a strong positive relationship between asset specificity and negotiated governance changes (i.e. considerate voice), and Delios et al. (2004) find that investments significantly reduce the likelihood of exit in international strategic alliances. To the best of our knowledge, no empirical studies directly investigate the effect of alliance-specific investments on aggressive and creative voices. However, Klein's (2000) account of the relationship between Fisher Body and General Motors suggests that the presence of specific investments reduces aggressive voice and increases creative voice. Therefore, we hypothesize:

H4 Compared with alliance managers who perceive low alliance-specific investments, alliance managers who perceive high alliance-specific investments are more likely to be patient and use considerate and creative voice but are less likely to exit, be opportunistic, use aggressive voice, and be neglectful.

\section{Available alternatives}

Available alternatives refer to the extent to which a partner firm possesses attractive alternatives that could enable managers to attain their firms' objectives (Ping, 1993, 1999). The availability of attractive alternatives provides managers with a source of power over the situation (Emerson, 1962), whereas a dearth of alternatives increases their dependence on counterparts (Emerson, 1962; Joshi and Arnold, 1997). The latter adverse situation pressures alliance managers to respond and preserve the current relationship (Provan and Skinner, 1989). Furthermore, alliance managers with attractive alternatives may feel less positive toward their present relationship and be less willing to act on the alliance's behalf (Withey and Cooper, 1989). Conversely, alliance managers with no alternative partners feel positively about the present relationship and act on the alliance's behalf. 
Because partners without attractive alternatives depend on their current relationships, managers have strong incentives to make the relationship work. They likely act constructively to protect the relationship by using responses such as creative voice (Amabile, 1988), considerate voice (Ping, 1997), and patience (Ping, 1993). Moreover, if managers perceive no other alternatives for achieving their firm's strategic objectives, they have no choice than to continue the current relationship, which decreases the likelihood of negligence and exit (Ping, 1993, 1999). The absence of attractive alternatives also increases the relative value of the alliance and decreases the likelihood that managers act destructively through opportunism or aggressive voice (Joshi and Arnold, 1997; Provan and Skinner, 1989).

Empirical research supports these relationships. Ping (1993) reveals that the lack of alternative attractiveness negatively influences exit, opportunism, and neglect but is not significantly associated with (considerate) voice or patience. However, the relationship with (considerate) voice later receives support (Ping, 1999). In addition, Hibbard et al. (2001) find that firms' dependence, measured in terms of alternative availability, positively influences patience and negatively influences neglect, though the negative relationship they hypothesize between dependence and venting (i.e. aggressive voice) is not statistically significant. However, case examples presented by Lax and Sebenius (1985) provide some anecdotal support for this negative relationship.

Other empirical research supports relationships between the availability of attractive alternatives and response strategies. In a study of R\&D alliances in the biotechnology industry, Deeds and Hill (1998) uncover a significant negative relationship between a partner's dependence due to a lack of alternatives and the use of opportunistic behavior. Similarly, Luo (2007) finds that in low growth industries, where the availability of alternatives is minimal, opportunism is more likely, and Joshi and Arnold (1997) show that when relational norms are low, the lack of alternatives increases opportunism. Provan and Skinner (1989) support a positive relationship between alternatives and neglect; Olk and Young (1997) suggest a lack of alternatives relates positively to exit. Finally, in a more general organizational context, Amabile (1988) argues that external pressures, such as the lack of alternatives, may push people to be more creative to solve an adverse situation. Therefore, we hypothesize:

H5 Compared with alliance managers who perceive many attractive alternatives, alliance managers who perceive few attractive alternatives are more likely to use patience and considerate and creative voices but are less likely to use exit, act opportunistically, use aggressive voice, and be neglectful.

\section{Interaction between alliance-specific investments and available alternatives}

Alliance-specific investments and the lack of available alternatives likely interact and influence the use of response strategies. Because they constitute two different types of exit barriers, they should reinforce each other (Ping, 1997). Therefore, when alliance-specific investments exist but attractive alternatives are lacking, alliance managers perceive greater dependence on the current relationship, which makes exit less likely. Constructive responses, such as considerate and creative voices, are far more likely. The high exit costs (Ping, 1997) make the current relationship appear more valuable, so managers should seek collaboration with their partner. In contrast, even if firms have made substantial alliance-specific investments, when they have other alternatives available, managers may act patiently and less aggressively and 
opportunistically, because they seek a balance between protecting their investments and waiting to act on more-attractive alternatives. If the firm has fewer alliance-specific investments but lacks available alternatives, managers' responses are constrained, requiring that they respond constructively. Finally, when a firm has made few alliance-specific investments but has plentiful alternatives, alliance managers likely exploit their dominant position by threatening to terminate the relationship without worrying about exit costs (Ping, 1997). These alliance managers may act to pursue their individual interests by engaging in opportunism, acting aggressively, or exiting the alliance (Ping, 1993). Therefore, we hypothesize:

H6 A positive interaction effect exists between alliance-specific investments and attractive alternative availability for an alliance manager's likelihood of using the seven response strategies. When alliance-specific investments are high (low), the effect of lack of attractive alternative availability is stronger (weaker).

\section{Methodology}

To test the hypotheses, we design an experimental scenario-based study, a methodology with a long tradition in the decision sciences that has proved useful for the study of major strategic decisions, because it provides an examination of the causal relationships between predictors and outcomes in controlled conditions (Bateman and Zeithaml, 1989; Croson et al., 2007). Managerial behavior depends on a variety of contextual influences (Bateman and Zeithaml, 1989), and these experiments control for confounding effects. Furthermore, the use of experiments eliminates endogeneity concerns (Echambadi et al., 2006). We also use scenarios, rather than real situations, because of the potentially sensitive nature of the questions; respondents may not answer questions about adverse situations in which they were involved openly (Strahan and Gerbasi, 1972). However, as recommended by Croson et al. (2007) and to improve the external validity, we develop scenarios that represent realistic alliance situations in which the predictors might operate. Furthermore, to avoid any priming effects, the respondents confront choices with uncertain and interdependent outcomes in settings in which the behavior, outcomes, and rules are not perfectly clear (Gundlach and Cadotte, 1994).

\section{Data collection}

We use MBA students as respondents, which may raise concerns about the degree to which alliance managers respond similarly (Peterson, 2001) but does not inhibit the validity of the extension of the EVLN typology, which requires an assessment of the response strategies' psychometric properties. For such an assessment, it is more appropriate to use a homogeneous group of respondents (Joshi and Arnold, 1997; Peterson, 2001). Furthermore, previous research provides evidence that managers' and students' responses converge in similar decision situations (Bateman and Zeithaml, 1989).

We collect the data during class meetings; if students agree to participate in the experiment about strategic alliances, they receive a document containing the scenario and a series of questions. The two-page document contains four parts: The first section includes a randomly selected scenario that introduces an adverse situation in a strategic alliance context; the following section features a list of items pertaining to the 
evaluation of response strategies; and the proceeding sections contain the manipulation check questions, as well as control variables. Participants read the instructions and scenario carefully and answer the questions as if they were the manager of the alliance. The sample consists of 303 respondents, with an average age of 26.3 years, 65.7 per cent of who are men.

\section{Scenario manipulations}

To capture the adverse situations, we manipulate economic satisfaction, social satisfaction, alliance-specific investments, and availability of alternatives. The experiment uses a four-factor (exchange variables) by two level (positive versus negative) between-subjects design, in which we combine the manipulations to form 16 different scenarios, from which we remove the all-positive scenario because the pretest indicates this situation is not perceived as adverse.

For the economic satisfaction manipulation, we vary the economic outcomes of the alliance; namely, the firm earns financial benefits either beyond or below its expectations (Geyskens and Steenkamp, 2000). The manipulation of social satisfaction varies the perception of the quality of relationship with the partner firm, such that a good relationship means the firms have developed a relationship characterized by trust, commitment, and adaptability (Geyskens and Steenkamp, 2000). To manipulate alliance-specific investments, we vary the extent to which the focal firm had made specific investments in the alliance as minor or substantial (Ping, 1993). Finally, we address the availability of alternatives by manipulating the extent to which the focal firm had access to other ways to realize its objectives, whether many alternatives available or only a few (Ping, 1993).

Consistent with the scenario-based experiment method (Perdue and Summers, 1986), we assess the degree to which respondents understand the scenarios with four manipulation-check items, such that each question pertains to a manipulation. To test for the effect of these manipulations, we subject the items to a four-factor multivariate analysis of variance (MANOVA). The effects of the four factors are strongly significant at 1 per cent, which indicates that the respondents understand the manipulations. Furthermore, to ensure the manipulations are independent and that there are no confounding effects, we examine the interaction terms (Perdue and Summers, 1986) and find that none of them is significant.

\section{Response strategy measures}

To operationalize the seven response strategies, we turn to existing scales and, when necessary, adapt them to the context of strategic alliances. We measure exit with items pertaining to whether the respondent intends to end the relationship or stop doing business with the partner (Ping, 1993, Geyskens and Steenkamp, 2000; Rusbult et al., 1988). The measures for opportunism, adapted from John (1984) and Ping (1993), include withholding information, exaggerating the adverse nature of the situation, and escaping from contractual obligations. Aggressive voice items refer to forcefully pushing a solution or being persistent (Hagedoorn et al., 1999). For creative voice, we use items related to the creation of innovative and creative solutions or fresh ideas (Zhou and George, 2001). To measure considerate voice, the items indicate working to create a consensus and finding a solution satisfactory and acceptable for everyone (Ping, 1993; Rusbult et al., 1982). We operationalize patience with items such as 
optimistically waiting for better times and trusting that the situation will solve by itself (Ping, 1993; Rusbult et al., 1982). For neglect, the items refer to not dealing with the issue, not putting additional effort into the relationship, and not presenting initiatives to improve the situation (Ping, 1993). All these measures use seven-point Likert scales, ranging from "I would definitely not react in this way" (1) to "I would definitely react in this way" (7). In Table I, we provide the wording of these items.

\section{Control variables}

We also measure several variables to control for individual differences, including an M-C2 version of the Marlowe-Crowne Social Desirability scale (Strahan and Gerbasi, 1972), because some response strategies may be more socially desirable (e.g. considerate voice) than others (e.g. opportunism). A single item assesses the perception of the severity of the problem, which can influence the use of response strategies (e.g. Richins, 1983). Furthermore, potentially influential demographic characteristics of the respondents, such as age and gender (e.g. Rusbult et al., 1988), are also included in the survey.

\section{Results}

We conduct two sets of analyses to examine the data. First, we analyze the extension of the EVLN model with aggressive voice, creative voice, and opportunism to determine if the three response strategies are distinct constructs. A series of confirmatory factor analyses (CFA) assesses the degree to which the seven-factor model fits the data better than alternative models. The CFAs also evaluate the convergent and discriminant validity of the response strategies. Second, to examine the relationships among the four exchange variables and the response strategies, we conduct a multivariate analysis of covariance (MANCOVA), followed by a series of univariate post-hoc analyses to test the hypotheses.

\section{Construct validity of the seven response strategies}

Using AMOS 7.0 for the CFA (Arbuckle, 2006; Byrne, 2001), we first estimate the most restrictive form of the full measurement model, which comprises 35 items to measure the seven response strategies (i.e. model 1). Each item was only allowed to load on its corresponding construct, and we posit that errors are uncorrelated. For scaling purposes, we fix the loading of the first indicators to 1. Maximum likelihood estimates the model parameters, because the data do not strongly violate multivariate normality assumptions (McDonald and Ho, 2002).

To assess the psychometric properties of the model, we examine the error variances, correlations, standard errors, goodness-of-fit indices, and factor loadings (Byrne, 2001). The error-variances are all positive and do not significantly differ from 0 . Correlations are not greater than 1 , and standard errors are not too large. Consistent with common practice (Byrne, 2001; Hu and Bentler, 1999), we use multiple indices to estimate model fit (see Table II). The normed chi-square, for which a value of less than 3.0 indicates good fit (Carmines and McIver, 1981), suggests acceptable fit with a value of 1.79. A root mean squared error of approximation (RMSEA) value of .051 (90 per cent confidence interval (CI): 0.046-0.056) and a square root mean residual (SRMR) value of 0.073 also are acceptable (Hu and Bentler, 1999). However, other goodness-of-fit indices indicate a relatively poor fit; the goodness-of-fit index $(\mathrm{GFI})=0.84$, adjusted goodness-of-fit index 


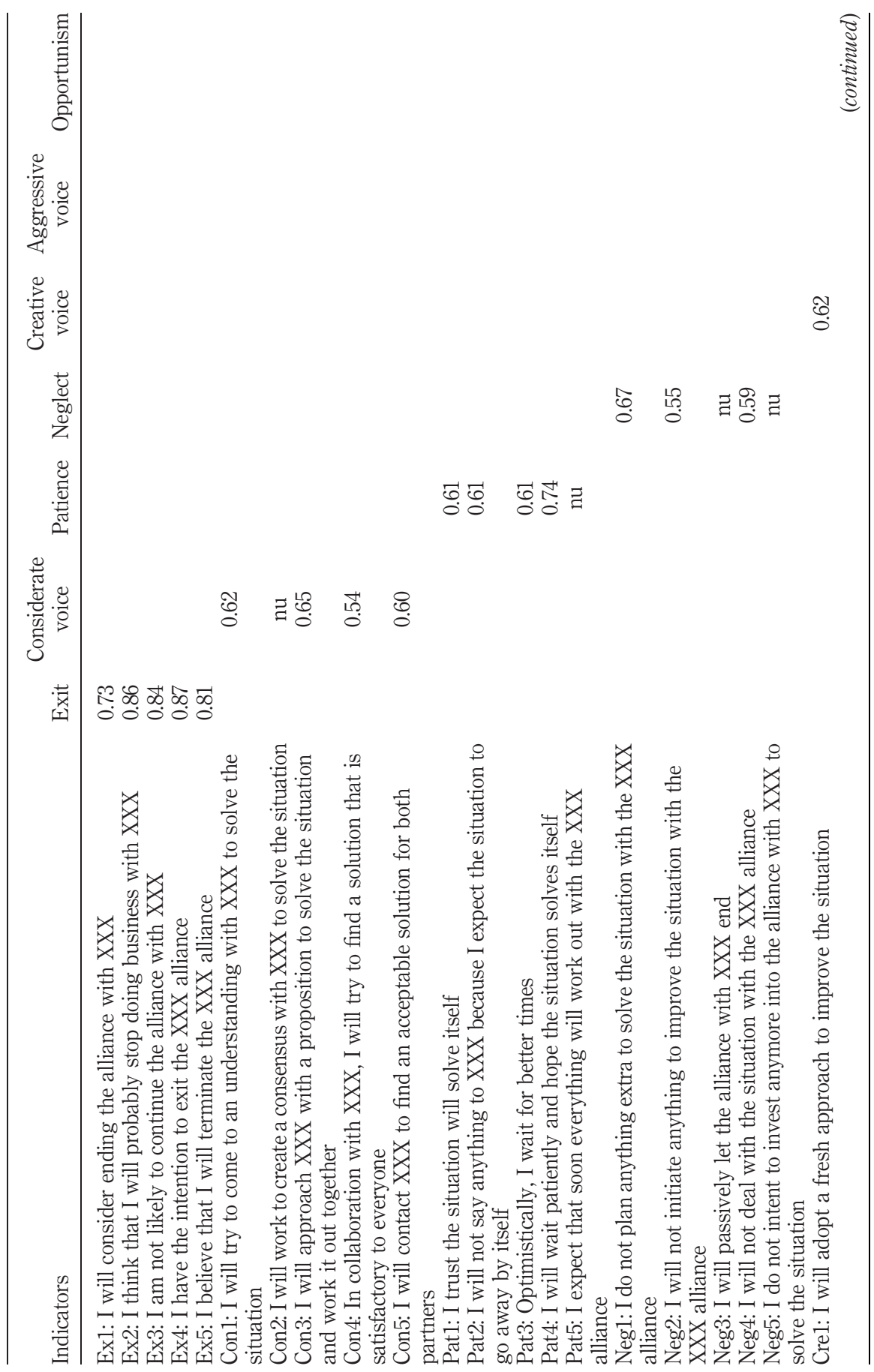

Table I. Standardized factor loadings for seven-factor response strategy model 


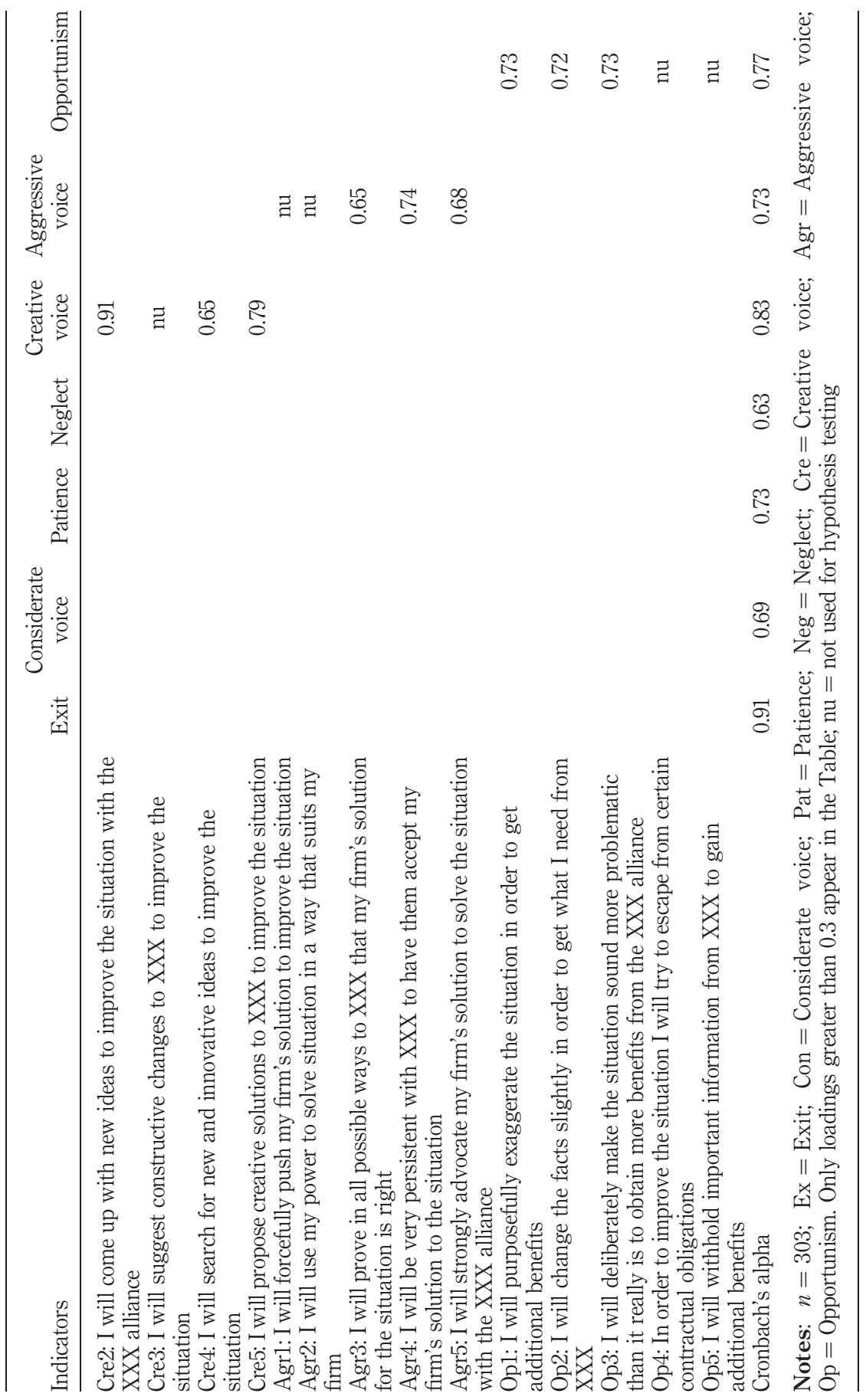




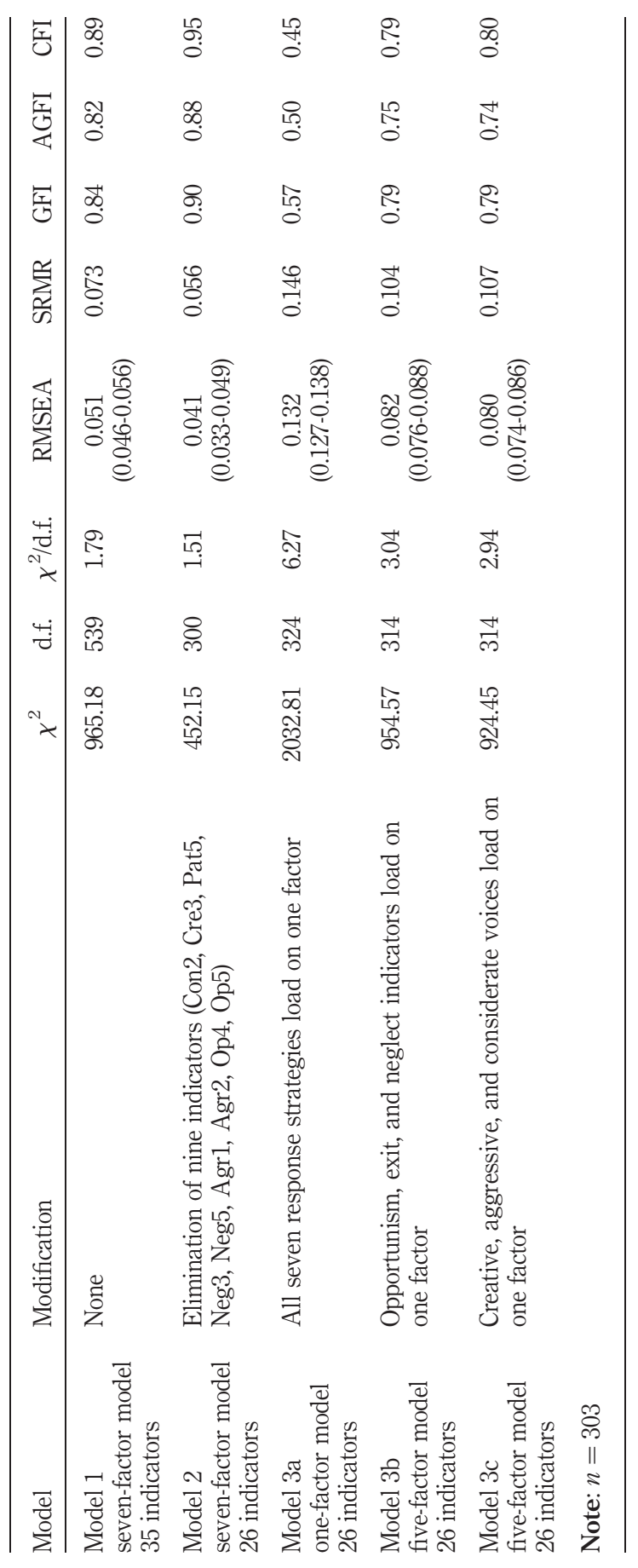

Table II. Results of AMOS analyses: goodness-of-fit statistics 
$(\mathrm{AGFI})=0.82$, and comparative fit index $(\mathrm{CFI})=0.89$ are lower than their respective threshold values (Hu and Bentler, 1999). More important, further analysis indicates that four item loadings (i.e. Cre3, Pat5, Neg3, and Neg5) fall below the acceptable threshold value of 0.5 (Fornell and Larcker, 1981), and five other items (i.e. Agr1, Agr2, Op4, Op5, and Con2) possess high cross-loadings, which necessitates a respecification of the model (Byrne, 2001).

We remove the nine invalid items and estimate a second seven-factor model with only 26 items. Our analysis of model 2 reveals no offending estimates. Moreover, compared with model 1, we find improved goodness-of-fit indices (see Table II). The normed chi-square value of 1.51 indicates good fit, as do the values of the other goodness-of-fit indices, namely, 0.90 (GFI), 0.88 (AGFI), 0.95 (CFI), 0.041 (RMSEA) (90 per cent CI: 0.033-0.049), and 0.056 (SRMR). To assess convergent validity, we examine the factor loadings; they are all highly significant and range from 0.54 to 0.91 (see Table I). To assess reliability, we use Cronbach's alpha coefficients; the results indicate values ranging from 0.69 to 0.91 , with only one exception (neglect $=0.63$ ), which suggests acceptable reliability (Nunnally and Bernstein, 1994). To assess discriminant validity, we compare the square root of the average variance extracted (AVE) with the correlations between the constructs (Fornell and Larcker, 1981). For model 2, the square root of the AVE values range from 0.60 to 0.82 , greater than any of the pairwise correlations $(|r|<0.51)$ reported in Table III.

Consistent with established procedures to assess the degree of discriminant validity (Byrne, 2001), we also estimate three alternative models (see Table II). In model 3a, we load all items on a single factor as a baseline. In model 3b, to establish the validity of the supplementary response strategies, we force opportunism, neglect, and exit to load on the same factor, whereas in the Model 3c, we combine the three types of voices on the same factor. The results indicate that the best fitting model is the seven-factor model with 26 items (model 2), as supported by chi-square difference tests. A comparison of model 2 $\left(\chi^{2}=452.15\right)$ with model 3a $\left(\chi^{2}=2032.81\right)$ yields a significant chi-square difference of $1,580.67(\phi<0.001)$. In addition, the significant differences in chi-square values with respect to model 3b $\left(\Delta \chi^{2}=502.43 ; p<0.001\right)$ and model $3 \mathrm{c}\left(\Delta \chi^{2}=472.31 ; p<0.001\right)$ indicate that opportunism, aggressive voice, and creative voice depict distinct constructs, distinguishable from the generic EVLN response strategies.

\section{Impact of exchange variables on response strategies}

As our second objective, we examine the effect of the four exchange variables on the seven response strategies. Because the response strategies are interrelated, we manipulate the exchange variables, and we use covariates to control for confounding effects, a MANCOVA is the most appropriate method (Hair et al., 1998). We conduct a general linear model MANCOVA because of the between-subject design and unequal cell sizes. Next, we ran univariate post-hoc analyses to test the hypotheses and interpret the effects of the exchange variables (Hair et al., 1998). In this analysis, we use the average scores for each of the seven response strategies as dependent variables and the dummy variables from the scenario manipulations as the fixed factors. Gender, age, problem severity, and social desirability enter the analysis as covariates. We test the interaction effects among the predictors and, for parsimony, remove those that are insignificant.

Before conducting the analysis, we examine the MANCOVA assumptions but find no violations. The sample of 303, with 15 cells, offers a sufficient number of 


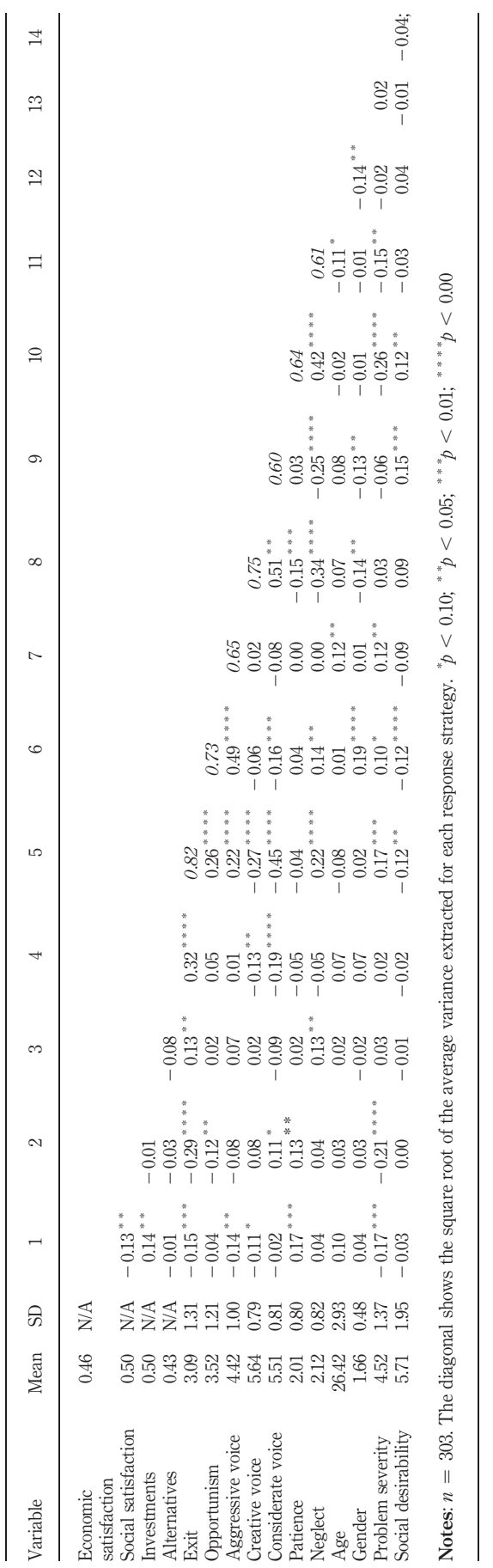

Table III.

Descriptive statistics and correlation matrix 
respondents to conduct the analysis (Hair et al., 1998). The omnibus MANCOVA test comparing the adverse situations indicates significant differences among the exchange variables. Specifically, the results reveal significant Wilks' lambdas for the four variables: economic satisfaction $(\Lambda=0.91, F=3.96, p<0.001)$, social satisfaction $(\Lambda=0.89, F=5.03, p<0.001)$, alliance-specific investments $(\Lambda=0.94, F=2.46$, $p<0.05)$, and alternative availability $(\Lambda=0.83, F=8.20, p<0.001)$. The two hypothesized two-way interactions are also significant: between economic and social satisfaction $(\Lambda=0.95, F=2.19, p<0.05)$ and between alliance-specific investments and alternative availability $(\Lambda=0.95, F=2.06, p<0.05)$. Furthermore, three of the four control variables are significant: gender $(\Lambda=0.92, F=3.55, p<0.001)$, problem severity $(\Lambda=0.93, F=3.00, p<0.01)$, and social desirability $(\Lambda=0.92, F=3.62$, $p<0.001)$. However, age is not significant $(\Lambda=0.96, F=1.55, p=0.15)$. The $F$-values of the corrected model, which reflect variations in the response strategies attributable to the exchange variables and covariates, show significant results for all seven-response strategies (see Table IV).

The post-hoc one-way ANOVAs and $t$-tests use a Bonferroni adjustment to control for Type I errors (Hair et al., 1998). The difference between low and high economic satisfaction is significant for exit $(F=7.76, p<0.001)$, aggressive voice $(F=7.82, p<0.001)$, and patience $(F=8.37, p<0.001)$ and marginally significant for creative voice $(F=3.48, p<0.10)$ (Table IV). That is, exit, aggressive voice, and creative voice are more likely among respondents who are dissatisfied with the economic performance of the alliance, whereas patience is more likely among respondents with a higher satisfaction level. The difference between low and high social satisfaction also is significant for exit $(F=26.80, p<0.001)$ and opportunism $(F=4.16, p<0.05)$ but marginally significant for aggressive voice $(F=2.71, p<0.10)$ and patience $(F=3.26, p<0.10)$. The post hoc analysis indicates that respondents who perceive lower quality relationship thus are more likely to choose exit and opportunism in response to an adverse situation, and those who have a high quality relationship are more likely to be patient.

We also uncover a negative interaction effect between economic and social satisfaction, such that the interaction is significant for exit $(F=7.33, p<0.001)$, creative voice $(F=5.39, p<0.05)$, and considerate voice $(F=8.21, p<0.001)$. Post hoc analysis indicates that respondents dissatisfied with the economic performance of the alliance but satisfied with its relational quality are less likely to exit and more likely to use creative and considerate voice, compared with those who are dissatisfied with relational quality. In contrast, respondents who are satisfied with economic performance are not likely to exit, though if they also are satisfied with the quality of the alliance relationship, they become less likely to use creative and considerate voice than if they were dissatisfied.

Furthermore, the findings indicate that the difference between few and substantial investments is significant for exit $(F=8.47, p<0.001)$, neglect $(F=7.23, p<0.01)$, and considerate voice $(F=6.70, p<0.05)$. Fewer alliance-specific investments increase a respondent's likelihood to dissolve the relationship and be neglectful, whereas more investments foster considerate voice. The difference between alternative availability and unavailability is significant for exit $(F=46.23, p<0.001)$, creative voice $(F=3.36, p<0.05)$, and considerate voice $(F=15.98, p<0.001)$. The post hoc analysis suggests that respondents are more likely to exit an adverse situation when 


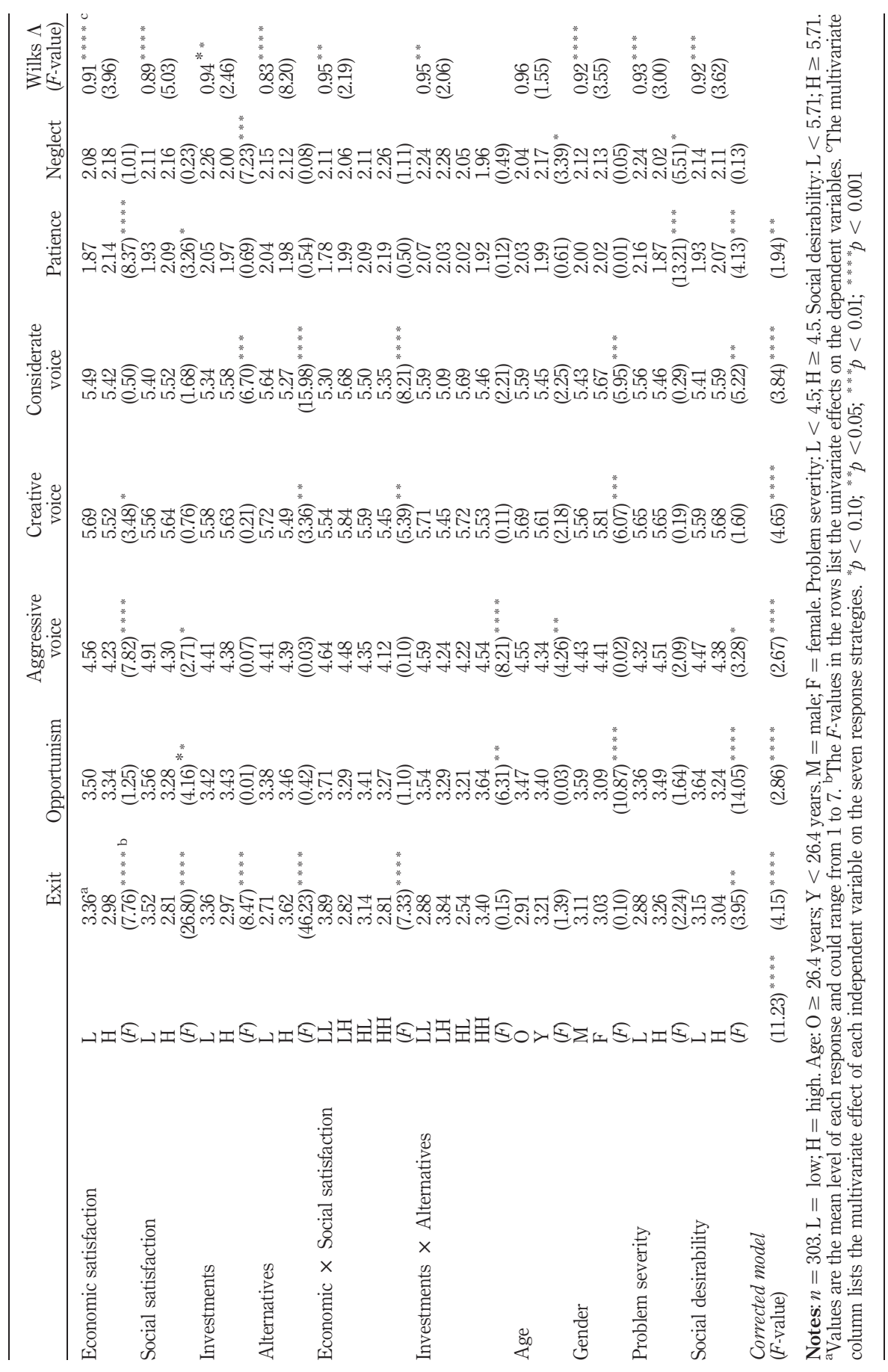

Table IV.

MANCOVA and post-hoc test results 
they have more alternatives available, whereas when they lack alternatives, they select responses such as creative and considerate voices.

The interaction between alliance-specific investments and alternative availability is significant for opportunism $(F=6.31, p<0.05)$ and aggressive voice $(F=8.21, p<0.001)$, such that respondents with significant alliance-specific investments and available alternatives tend to behave opportunistically and aggressively voice their concerns. However, when they lack alternatives, they become less opportunistic and aggressive. Those respondents without significant alliance-specific investments but with alternatives available are not likely to act opportunistically or use aggressive voice; when they lack alternatives, they may use these responses to a certain extent.

Of the control variables, gender, problem severity, and social desirability have significant effects. Gender influences opportunism $(F=10.87, p<0.001)$, creative voice $(F=6.07, p<0.01)$, and considerate $(F=5.93, p<0.01)$, as confirmed by post-hoc, one-way ANOVAs that show male respondents are more likely to use opportunism and less likely to use creative and considerate voices than are female respondents. Problem severity also influences patience $(F=13.21, p<0.001)$ and neglect $(F=5.51, p<0.05)$; the post-hoc $t$-tests reveal that the more severe the perceptions of the situation, the less likely respondents are to be patient and neglectful. Finally, as expected, social desirability has a significant effect on the likelihood of several response strategies: exit $(F=3.95, p<0.05)$, opportunism $(F=14.05$, $p<0.001)$, considerate voice $(F=5.22, p<0.05)$, patience $(F=4.13, p<0.01)$, and marginally aggressive voice $(F=3.28, p<0.10)$. Respondents with high scores on the social desirability scale tend not to exit, act opportunistically, or use aggressive voice but instead employ considerate voice and are more patient than respondents with low social desirability scores.

A breakdown of the hypothesis tests shows that of the 28 hypothesized direct relationships, 14 (50.0 per cent) are supported, 14 are not significant, and none contradicts the hypothesized direction (see Table V). Of the 14 interaction effects hypothesized, five (35.7 per cent) receive support, and the remainder is not significant. We discuss these results in more detail in the next section.

\section{Discussion}

Extant alliance research demonstrates that partners can overcome adverse situations and steer their strategic alliances toward success. The central objective of our research is to provide insight into which response strategy alliance managers use to react to undesirable circumstances. Therefore, we refine the EVLN typology and extend it to seven response strategies. We split voice into three different forms - considerate, creative, and aggressive - and add opportunism. The data support the extended typology and indicate that adverse situations, through the four exchange variables, directly and interactively influence the use of response strategies.

Our findings validate but also extend prior alliance research on response strategies. Together, they provide support for the investment model (Rusbult et al., 1982), which suggests that exchange conditions influence decision making within strategic alliances, as in other contexts. Our results are consistent with those of Ping $(1993,1999)$ and Hibbard et al. (2001), who show that dissatisfaction and alternative availability stimulate exit. They also find that alliance-specific investment foster considerate voice 
and reduce patience (Ping, 1993, 2003). Our findings further validate those of Geyskens and Steenkamp (2000), who reveal that economic satisfaction reduces the likelihood of exit and fosters patience, whereas social satisfaction reduces the likelihood of both exit and patience (see Table V).

Our findings further reveal some novel insights. Ping (1993) finds no significant effect of satisfaction on opportunism, whereas we suggest that his result may have been caused by a confounding effect between economic and social satisfaction. By distinguishing between these forms of satisfaction, we reveal that social satisfaction only, and not economic satisfaction, stimulates the use of opportunism. Contrary to the surprising findings of Ping (1993), we also find that alliance-specific investments, not just lack of alternatives, have negative effects on exit. As hypothesized, we uncover a negative effect of social satisfaction on aggressive voice (not significant in Hibbard et al., 2001) and a negative effect of economic satisfaction on creative voice (not significant in Geyskens and Steenkamp, 2000). Furthermore, by splitting voice into three distinct types, we present a finer-grained understanding of this complex construct (Kay, 1989; Withey and Cooper, 1989). In terms of satisfaction, aggressive voice depends on both economic and social satisfaction, whereas creative voice is influenced only by economic satisfaction, and considerate voice receives no impact from either type. Similarly, in terms of exit barriers, alliance-specific investments and a lack of attractive alternatives influence considerate voice, only the lack of alternatives affects creative voice, and neither barrier influences aggressive voice.

The presence of negative interaction effects between economic and social satisfaction, described by Geyskens and Steenkamp (2000) in the case of exit, also appears to affect creative voice and considerate voice. Finally, we find a positive interaction effect between alliance-specific investments and lack of alternatives on opportunism and aggressive voice, relationships that have never been tested before.

\section{Additional insights}

Two of our findings deserve further elaboration. First, consistent with prior response strategy research (Geyskens and Steenkamp, 2000; Hagedoorn et al., 1999; Hibbard et al., 2001; Ping, 1993, 1999; Rusbult et al., 1988), we uncover a relatively high number of insignificant relationships among exchange variables and response strategies. One explanation for this result, offered by Hagedoorn et al. (1999), suggests that response strategies may be organized around the circumference of a circle. Consistent with such a circumplex structure, the impact of an exchange variable should follow a sinusoidal relationship, implying a pattern of significant positive, insignificant, significant negative associations (Hagedoorn et al., 1999). Our results seem to exhibit such a structure, in that the pattern of correlations among the seven response strategies takes the following order: exit, opportunism, aggressive voice, creative voice, considerate voice, patience, and neglect - a pattern also observed in Withey and Cooper's (1989) and Ping's (1999) results. However, further research should investigate the structure of and interrelatedness among these response strategies.

Second, we adapt the investment model developed by Rusbult et al. (1982) to the context of strategic alliances. This model focuses on relationship-level explanations, but we also find significant effects of individual-level variables, such as gender and social desirability. Therefore, alliance conditions and individual characteristics both appear to influence the use of response strategies. These findings suggest that research 


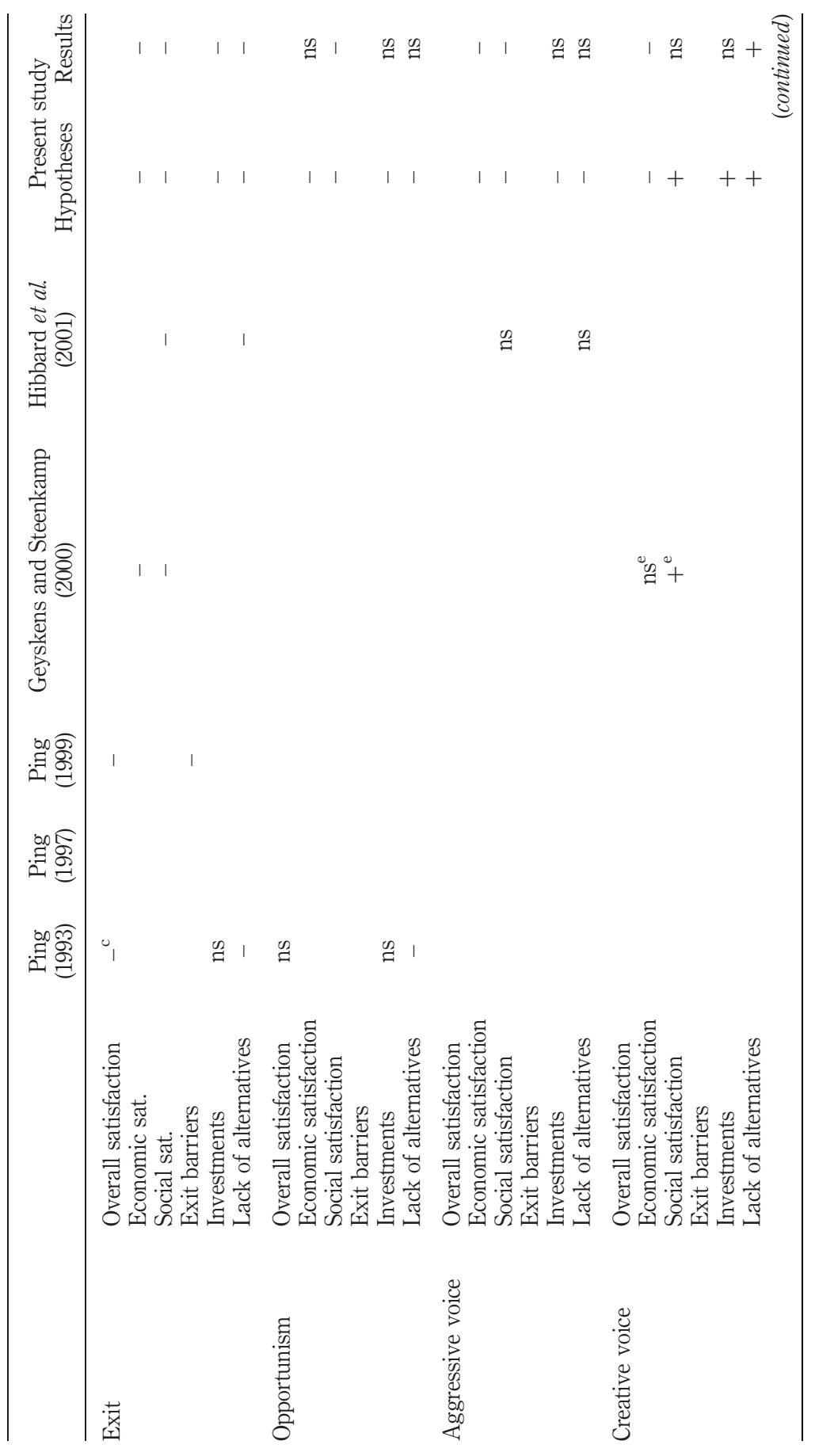

Table V.

Hypothesized direct effects and empirical results $^{\mathrm{a}}$ 


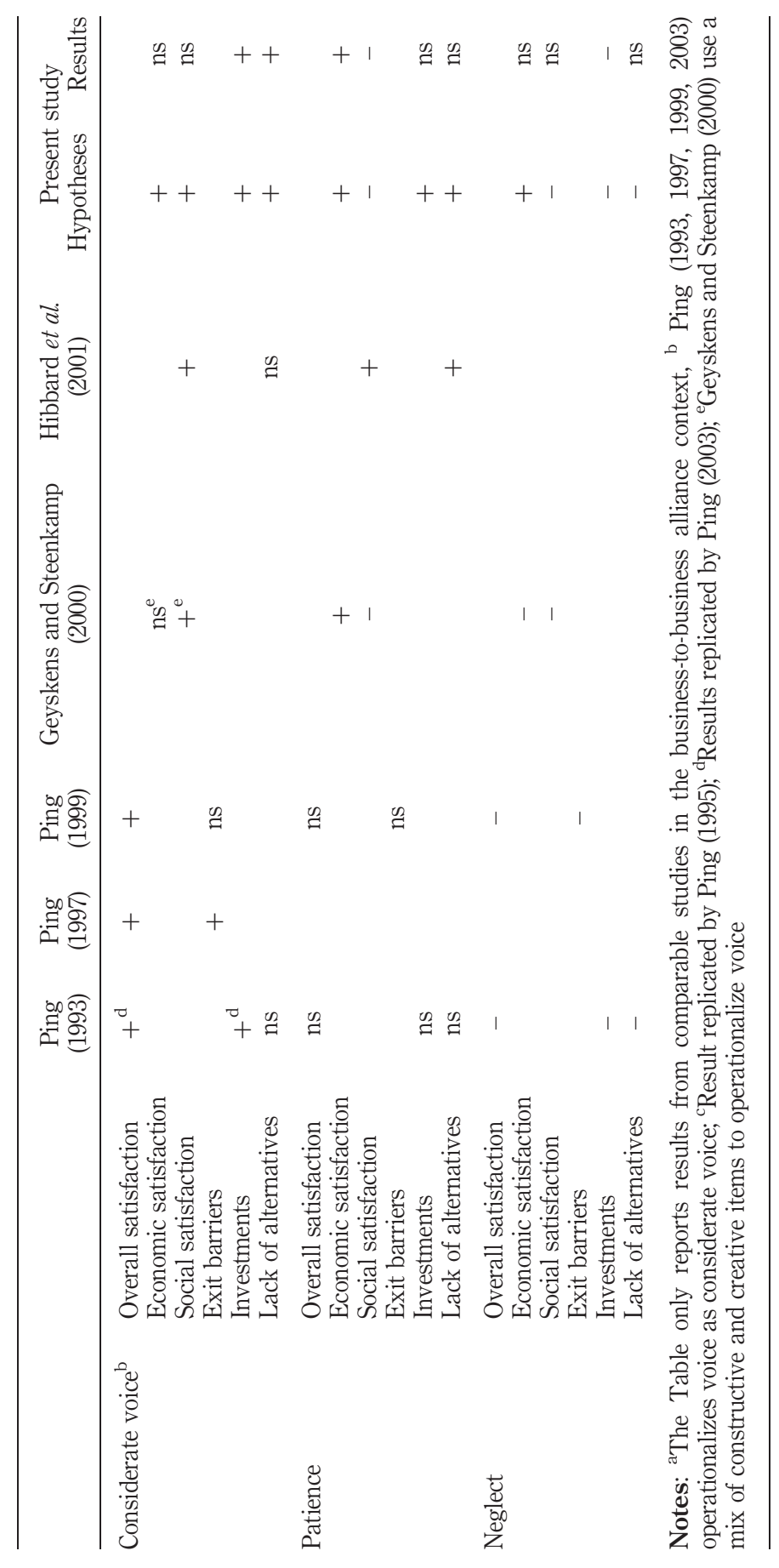

Table V. 
might complement the investment model with individual attributes. Withey and Cooper (1989) similarly find that locus of control, as a personality trait, has a significant effect on voice, loyalty, and neglect. Other relevant individual traits, such as leadership style and attributions, should be investigated as well. Furthermore, by using an experimental design, we control for the impact of environmental conditions (Croson et al., 2007) and eliminate potentially influential external effects (Luo, 2007). Developing and testing hypotheses that specify relationships among environmental conditions, relationship factors, manager traits, and response strategy would be consistent with Chatman's (1989) recommendations to improve interactional organizational research.

\section{Limitations}

Additional research should replicate our results with practicing alliance managers. Although the use of MBA students is appropriate for our research objectives, input from alliance managers would be valuable. Furthermore, because we manipulate the independent variables, the external validity of the findings may be of concern. However, given the theory-development and causality objectives of this study, an experiment remains more suitable than other data collection methods (Croson et al., 2007). We also measure behavioral intentions rather than actual behaviors. Although intentions are not always flawless predictors of behavior, our approach attempts to assess the intensity of the likelihood of response strategies, an objective achieved more readily by measuring behavioral intention rather than behaviors. However, a field study focusing on alliance managers' behavior would complement our findings.

The scenario-based experiment we use is cross-sectional, which prevents us from providing explanations of response strategy dynamics. For example, research might design longitudinal experiments to examine the evolution of alliance managers' responses over time to shifting adverse situations. In addition, building on the work of Doz (1996) and Ariño and De la Torre (1998), research could conduct longitudinal case studies to explore whether partners' interactions depict particular response strategy patterns. The identification of such patterns may help alliance managers anticipate their counterparts' behavior and overcome adverse situations more effectively.

Within alliance literature, the so-called "structure perspective" states that initial alliance conditions influence alliance performance. More recently, a process perspective has emerged, advocating that managers can deal with unforeseen circumstances and overcome the limitations of initial alliance designs. Our study contributes to this process perspective by highlighting the various response strategies that alliance managers use to deal with adverse situations and their antecedents.

\section{Note}

1. Leck and Saunders (1992) propose the term "patience" to refer to loyalty as a behavioral response and reserve the term "loyalty" for the attitudinal component of the construct, in line with Hirschman's (1970) original conceptualization.

\section{References}

Amabile, T.M. (1988), "A model of creativity and innovation in organizations", in Staw, B.M. and Cummings, L.L. (Eds), Research in Organizational Behavior, Vol. 10, JAI Press, Greenwich, CT, pp. 123-67. 
Anderson, E. (1988), "Transaction costs as determinants of opportunism in integrated and independent sales forces", Journal of Economic Behavior and Organization, Vol. 9 No. 3, pp. 247-64.

Anderson, E. and Weitz, B. (1992), "The use of pledges to build and sustain commitment in distribution channels", Journal of Marketing Research, Vol. 29 No. 1, pp. 18-34.

Anderson, J.C. and Narus, J.A. (1990), "A model of distributor firm and manufacturer firm", Journal of Marketing, Vol. 54 No. 1, pp. 42-58.

Arbuckle, J.L. (2006), Amos 7.0 User's Guide, Amos Development Corporation, Chicago, IL.

Ariño, A. and De la Torre, J. (1998), "Learning from failure: towards an evolutionary model of collaborative ventures”, Organization Science, Vol. 9 No. 3, pp. 306-25.

Ariño, A., De la Torre, J. and Ring, P.S. (2001), "Relational quality: managing trust in corporate alliances”, California Management Review, Vol. 44 No. 1, pp. 109-31.

Bateman, T.S. and Zeithaml, C.P. (1989), "The psychological context of strategic decisions: a model and convergent experimental findings", Strategic Management Journal, Vol. 10 No. 1, pp. 59-74.

Blau, P.M. (1964), Exchange and Power in Social Life, Wiley, New York, NY.

Brouthers, K.D. and Bamossy, G.J. (2006), "Post-formation processes in Eastern and Western European joint ventures”, Journal of Management Studies, Vol. 43 No. 2, pp. 203-29.

Buckley, P.J. (1999), "Alternatives to decline, threat or scarcity: exit, voice, loyalty and institutional response", Management International Review, Vol. 39 No. 1, pp. 45-53.

Byrne, B.M. (2001), Structural Equation Modeling with AMOS: Basic Concepts, Application, and Programming, Lawrence Erlbaum Associates, Mahwah, NJ.

Carmines, E.G. and McIver, J.P. (1981), “Analyzing models with unobserved variables: analysis of covariance structures", in Bohrnstedt, G.W. and Borgatta, E.F. (Eds), Social Measurement: Current Issues, Sage, Beverly Hills, CA, pp. 65-115.

Chatman, J.A. (1989), "Improving interactional organizational research: a model of person-organization fit", Academy of Management Review, Vol. 14 No. 3, pp. 333-49.

Cropanzano, R. and Mitchell, M.S. (2005), "Social exchange theory: an interdisciplinary review", Journal of Management, Vol. 31 No. 6, pp. 874-900.

Croson, R., Anand, J. and Agarwal, R. (2007), "Using experiments in corporate strategy research", European Management Review, Vol. 4 No. 3, pp. 173-81.

Das, T.K. (2005), "Deceitful behaviors of alliance partners: potential and prevention", Management Decision, Vol. 43 No. 5, pp. 706-19.

Das, T.K. (2006), "Strategic alliance temporalities and partner opportunism", British Journal of Management, Vol. 17 No. 1, pp. 1-21.

Das, T.K. and Kumar, R. (2007), "Learning dynamics in the alliance development process", Management Decision, Vol. 45 No. 4, pp. 684-707.

Das, T.K. and Kumar, R. (2010), "Inter-partner sensemaking in strategic alliances: managing cultural differences and internal tensions", Management Decision, Vol. 48 No. 1, pp. 17-36.

Das, T.K. and Teng, B.-S. (2000), "A resource-based theory of strategic alliances", Journal of Management, Vol. 26 No. 1, pp. 31-61.

De Rond, M. and Bouchikhi, H. (2004), "On the dialectics of strategic alliances", Organization Science, Vol. 15 No. 1, pp. 56-69.

Deeds, D.L. and Hill, C.W.L. (1998), "An examination of opportunistic action within research alliances: evidence from the biotechnology industry", Journal of Business Venturing, Vol. 14 No. 2, pp. 141-63. 
Delios, A., Inkpen, A.C. and Ross, J. (2004), "Escalation in international strategic alliances", Management International Review, Vol. 44 No. 4, pp. 457-79.

Doz, Y.L. (1996), "The evolution of cooperation in strategic alliances: initial conditions or learning processes?”, Strategic Management Journal, Vol. 17, special issue, pp. 55-83.

Dwyer, F.R., Schurr, P.H. and Oh, S. (1987), "Developing buyer-seller relationships", Journal of Marketing, Vol. 51 No. 2, pp. 11-27.

Echambadi, R., Campbell, B. and Agarwal, R. (2006), "Encouraging best practice in quantitative management research: an incomplete list of opportunities", Journal of Management Studies, Vol. 43 No. 8, pp. 1801-20.

Emerson, R.M. (1962), "Power-dependence relations”, American Sociological Review, Vol. 27 No. 1, pp. 31-41.

Farrell, D. (1983), "Exit, voice, loyalty, and neglect as responses to job dissatisfaction: a multidimensional-scaling study", Academy of Management Journal, Vol. 26 No. 4, pp. 596-607.

Farrell, D. and Rusbult, C.E. (1992), "Exploring the exit, voice, loyalty, and neglect typology: the influence of job satisfaction, quality of alternatives, and investment size", Employee Responsibilities and Rights Journal, Vol. 5 No. 3, pp. 201-18.

Fornell, C. and Larcker, D.F. (1981), "Evaluating structural equation models with unobservable variables and measurement error", Journal of Marketing Research, Vol. 18 No. 1, pp. 39-50.

Geyskens, I. and Steenkamp, J.-B.E.M. (2000), "Economic and social satisfaction: measurement and relevance to marketing channel relationships", Journal of Retailing, Vol. 76 No. 1, pp. 11-32.

Geyskens, I., Steenkamp, J.-B.E.M. and Kumar, N. (1999), "A meta-analysis of satisfaction in marketing channel relationships”, Journal of Marketing Research, Vol. 36 No. 2, pp. 223-38.

Griffith, D.A. (2006), "Attributions of non-cooperative incidents and response strategies: the role of national character”, Journal of World Business, Vol. 41 No. 4, pp. 356-67.

Gulati, R., Khanna, T. and Nohria, N. (1994), "Unilateral commitments and the importance of process in alliances”, Sloan Management Review, Vol. 35 No. 3, pp. 61-9.

Gundlach, G.T. and Cadotte, E.R. (1994), "Exchange interdependence and interfirm interaction: research in a simulated channel setting”, Journal of Marketing Research, Vol. 31 No. 4, pp. 516-32.

Hagedoorn, M., Van Yperen, N.W., Van de Vliert, E. and Buunk, B.P. (1999), "Employees' reactions to problematic events: a circumplex structure of five categories of responses, and the role of job satisfaction”, Journal of Organizational Behavior, Vol. 20 No. 3, pp. 309-21.

Hair, J.F., Anderson, R.E., Tatham, R.L. and Black, W.C. (1998), Multivariate Data Analysis, 5th ed., Prentice-Hall, Englewood Cliffs, NJ.

Hibbard, J.D., Kumar, N. and Stern, L.W. (2001), "Examining the impact of destructive acts in marketing channel relationships", Journal of Marketing Research, Vol. 38 No. 1, pp. 45-61.

Hirschman, A.O. (1970), Exit, Voice and Loyalty: Responses to Decline in Firms, Organizations and States, Harvard University Press, Cambridge, MA.

Hoang, H. and Rothaermel, F.T. (2005), "The effect of general and partner-specific alliance experience on joint R\&D project performance”, Academy of Management Journal, Vol. 48 No. 2, pp. 332-45.

Hu, L. and Bentler, P.M. (1999), "Cutoff criteria for fit indexes in covariance structure analysis: conventional criteria versus new alternatives", Structural Equation Modeling, Vol. 6 No. 1, pp. 1-55. 
John, G. (1984), "An empirical investigation of some antecedents of opportunism in a marketing channel”, Journal of Marketing Research, Vol. 21 No. 3, pp. 278-89.

Johnson, J.L., Cullen, J.B. and Sakano, T. (1996), "Opportunistic tendencies in IJVs with the Japanese: the effects of culture, shared decision making, and relationship age", The International Executive, Vol. 38 No. 1, pp. 79-94.

Joshi, A.W. and Arnold, S.J. (1997), "The impact of buyer dependence on buyer opportunism in buyer-supplier relationships: the moderating role of relational norms", Psychology and Marketing, Vol. 14 No. 8, pp. 823-45.

Judge, W.Q. and Dooley, R. (2006), "Strategic alliance outcomes: a transaction-cost economics perspective", British Journal of Management, Vol. 17 No. 1, pp. 23-37.

Kay, P. (1989), "An act frequency study of exit, voice, loyalty and neglect”, unpublished honors thesis, Department of Psychology, Queen's University, Kingston, Ontario.

Klein, B. (2000), "Fisher-General Motors and the nature of the firm", Journal of Law and Economics, Vol. 43 No. 1, pp. 105-41.

Klein, B., Crawford, R.G. and Alchian, A.A. (1978), "Vertical integration, appropriable rents, and the competitive contracting process", Journal of Law \& Economics, Vol. 21 No. 2, pp. 297-326.

Lax, D.A. and Sebenius, J.K. (1985), "The power of alternatives or the limits to negotiation", Negotiation Journal, Vol. 1 No. 2, pp. 163-79.

Leck, J.D. and Saunders, D.M. (1992), "Hirschman's loyalty: attitude or behavior?", Employee Responsibilities and Rights Journal, Vol. 5 No. 3, pp. 219-30.

Lee, D.-J., Lee, M. and Suh, J. (2007), "Benevolence in the importer-exporter relationship: moderating role of value similarity and cultural familiarity", International Marketing Review, Vol. 24 No. 6, pp. 657-77.

Lewis, M.C. and Lambert, D.M. (1991), "A model of channel member performance, dependence, and satisfaction”, Journal of Retailing, Vol. 67 No. 2, pp. 205-25.

Lui, S.S. and Ngo, H.Y. (2004), "The role of trust and contractual safeguards on cooperation in non-equity alliances", Journal of Management, Vol. 30 No. 4, pp. 471-85.

Luo, Y.D. (2007), "Are joint venture partners more opportunistic in a more volatile environment?", Strategic Management Journal, Vol. 28 No. 1, pp. 39-60.

McDonald, R.P. and Ho, M.-H.R. (2002), "Principle and practice in reporting structural equation analyses", Psychology Methods, Vol. 7 No. 1, pp. 64-82.

Makino, S., Chan, C.M., Isobe, T. and Beamish, P.W. (2007), "Intended and unintended termination of international joint ventures", Strategic Management Journal, Vol. 28 No. 11, pp. 1113-32.

Morgan, R.M. and Hunt, S.D. (1994), "The commitment-trust theory of relationship marketing”, Journal of Marketing, Vol. 58 No. 3, pp. 20-38.

Nunnally, J.C. and Bernstein, I.H. (1994), Psychometric Theory, 3rd ed., McGraw-Hill, New York, NY.

Olk, P. and Young, C. (1997), "Why members stay in or leave an R\&D consortium: performance and conditions of membership as determinants of continuity", Strategic Management Journal, Vol. 18 No. 11, pp. 855-77.

Park, S.H. and Ungson, G.R. (1997), "The effect of national culture, organizational complementarity, and economic motivation on joint venture dissolution”, Academy of Management Journal, Vol. 40 No. 2, pp. 279-307. 
Perdue, B.C. and Summers, J.O. (1986), "Checking the success of manipulations in marketing experiments", Journal of Marketing Research, Vol. 23 No. 4, pp. 317-26.

Peterson, R.A. (2001), "On the use of college students in social science research: insights from a second-order meta-analysis”, Journal of Consumer Research, Vol. 28 No. 3, pp. 450-61.

Ping, R.A. (1993), "The effects of satisfaction and structural constraints on retailer exiting, voice, loyalty, opportunism, and neglect", Journal of Retailing, Vol. 69 No. 3, pp. 320-52.

Ping, R.A. (1995), "Some uninvestigated antecedents of retailer exit intention", Journal of Business Research, Vol. 34, pp. 171-80.

Ping, R.A. (1997), "Voice in business-to-business relationships: cost-of-exit and demographic antecedents”, Journal of Retailing, Vol. 73 No. 2, pp. 261-81.

Ping, R.A. (1999), "Unexplored antecedents of exiting in a marketing channel", Journal of Retailing, Vol. 75 No. 2, pp. 218-41.

Ping, R.A. (2003), "Antecedents of satisfaction in a marketing channel”, Journal of Retailing, Vol. 79 No. 4, pp. 237-48.

Porter, M.E. (1980), Competitive Strategy, Free Press, New York, NY.

Pressey, A.D. and Qu, X.X. (2007), "Buyer-supplier relationship dissolution: the Chinese context", Journal of Business \& Industrial Marketing, Vol. 22 No. 2, pp. 107-17.

Provan, K.J. and Skinner, S.J. (1989), "Interorganizational dependence and control as predictors of opportunism in dealer-supplier relations”, Academy Management Journal, Vol. 32 No. 1, pp. 202-12.

Reuer, J.J. and Ariño, A. (2002), “Contractual renegotiations in strategic alliances”, Journal of Management, Vol. 28 No. 1, pp. 47-68.

Richins, M.L. (1983), "Negative word-of-mouth by dissatisfied consumers: a pilot study", Journal of Marketing, Vol. 47 No. 1, pp. 68-78.

Rusbult, C.E. and Zembrodt, I.M. (1983), "Responses to dissatisfaction in romantic involvements: a multidimensional-scaling analysis", Journal of Experimental Social Psychology, Vol. 19 No. 3, pp. 274-93.

Rusbult, C.E., Zembrodt, I.M. and Gunn, L.K. (1982), "Exit, voice, loyalty, and neglect: responses to dissatisfaction in romantic involvements", Journal of Personality and Social Psychology, Vol. 43 No. 6, pp. 1230-42.

Rusbult, C.E., Farrell, D., Rogers, G. and Mainous, A.G. III (1988), "Impact of exchange variables on exit, voice, loyalty, and neglect: an integrative model of responses to declining job-satisfaction”, Academy of Management Journal, Vol. 31 No. 3, pp. 599-627.

Strahan, R. and Gerbasi, K.C. (1972), "Short, homogeneous versions of Marlow-Crowne social desirability scale", Journal of Clinical Psychology, Vol. 28 No. 2, pp. 191-3.

Thibaut, J.W. and Kelley, H.H. (1959), The Social Psychology of Groups, Wiley, New York, NY.

Wathne, K.H. and Heide, J.B. (2000), "Opportunism in interfirm relationships: forms, outcomes, and solutions", Journal of Marketing, Vol. 64 No. 4, pp. 36-51.

Williamson, O.E. (1993), "Transaction cost economics and organization theory”, Industrial and Corporate Change, Vol. 2 No. 1, pp. 107-56.

Withey, M.J. and Cooper, W.H. (1989), "Predicting exit, voice, loyalty, and neglect", Administrative Science Quarterly, Vol. 34 No. 4, pp. 521-39.

Zhou, J. and George, J.M. (2001), "When job dissatisfaction leads to creativity: encouraging the expression of voice”, Academy of Management Journal, Vol. 44 No. 4, pp. 682-96. 


\begin{abstract}
About the authors
Brian Tjemkes is an Assistant Professor in the Department of Management and Organization of the Faculty of Economics and Business Administration, at the VU University Amsterdam, The Netherlands. He received his $\mathrm{PhD}$ in Business Administration from Radboud University Nijmegen. His dissertation focuses on the relationships among value creation, value appropriation, and alliance performance. He has published in the Journal of Management Studies, among others. His research interests include the management and performance of strategic alliances and asymmetrical relationships.

Olivier Furrer is Associate Professor of Strategic Management at the Nijmegen School of Management of the Radboud University Nijmegen, The Netherlands. He previously held positions at the University of Illinois at Urbana-Champaign (USA), Birmingham (UK), Lausanne and Neuchâtel (Switzerland). He holds a PhD from the University of Neuchâtel. He has published in the Journal of International Business Studies, Management International Review, and International Journal of Management Reviews, among others. His current research interests are in the areas of international corporate social responsibilities and response strategies in problematic strategic alliances. Olivier Furrer is the corresponding author and can be contacted at: o.furrer@fm.ru.nl
\end{abstract}

To purchase reprints of this article please e-mail: reprints@emeraldinsight.com Or visit our web site for further details: www.emeraldinsight.com/reprints 